Conf $-941129--24$

UCRL- JC- 118776

PREPRINT

\title{
AFM Studies of a New Type of Radiation Defect on Mica Surfaces Caused by Highly Charged Ion Impact
}

\author{
C. Ruehlicke \\ M. A. Briere \\ D. Schneider
}

Prepared for Submittal to

Thirteenth International Conference on the Application of Accelerators in Research and Industry

November 7-10, 1994, Denton, TX

September 28, 1994

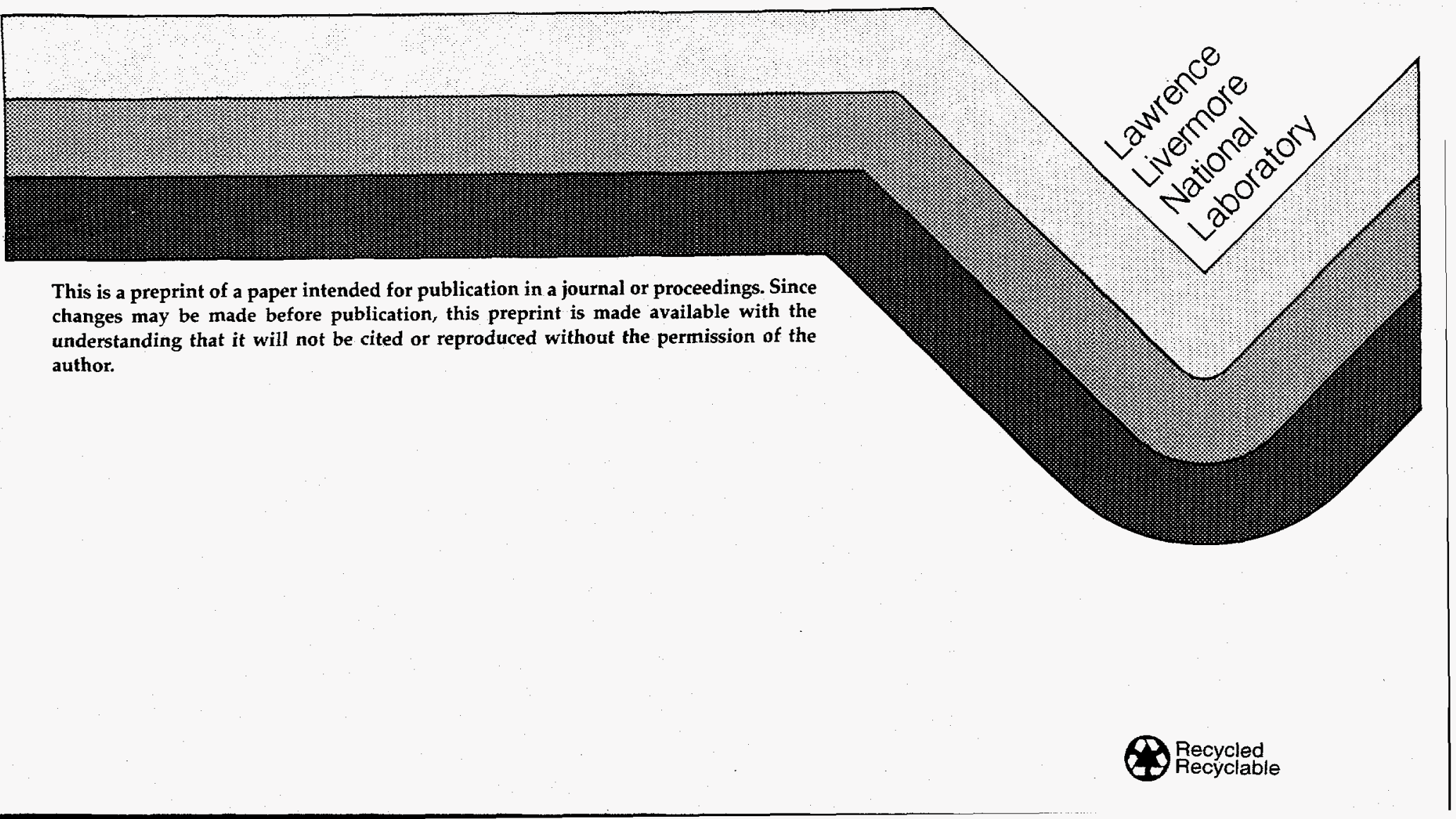




\section{DISCLAIMER}

This document was prepared as an account of work sponsored by an agency of the United States Government. Neither the United States Government nor the University of California nor any of their employees, makes any warranty, express or implied, or assumes any legal liability or responsibility for the accuracy, completeness, or usefulness of any information, apparatus, product, or process disclosed, or represents that its use would not infringe privately owned rights. Reference herein to any specific commercial product, process, or service by trade name, trademark, manufacturer, or otherwise, does not necessarily constitute or imply its endorsement, recommendation, or favoring by the United States Government or the University of California. The views and opinions of authors expressed herein do not necessarily state or reflect those of the United States Government or the University of California, and shall not be used for advertising or product endorsement purposes. 


\section{DISCLAIMER}

Portions of this document may be illegible in electronic image products. Images are produced from the best available original document. 


\title{
AFM STUDIES OF A NEW TYPE OF RADIATION DEFECT ON MICA SURFACES CAUSED BY HIGHLY CHARGED ION IMPACT
}

\author{
C. RUEHLICKE* , M.A. BRIERE, D. SCHNEIDER \\ Lawrence Livermore National Laboratory, California 94550, USA
}

Radiation induced defects on mica caused by the impact of slow very highly charged ions (SVHCI) have been investigated with an atomic force microscope (AFM). Freshly cleaved surfaces of different types of muscovite were irradiated with SVHCI extracted from the LLNL electron beam ion trap (EBIT) at velocities of ca. $2 \mathrm{keV} / \mathrm{amu}$. Atomic force microscopy of the surface reveals the formation of blisterlike defects associated with single ion impact. The determined defect volume which appears to increase linearly with the incident charge state and exhibits a threshold incident charge state has been determined using the AFM. These results indicate that target atoms are subjected to mutual electrostatic repulsion due to ionization through potential electron emission upon approach of the ion. If the repulsion leads to permanent atomic displacement, surface defects are formed.

\footnotetext{
* also Universität Bielefeld, 33615 Bielefeld, Germany
} 


\section{Introduction}

Radiation defects in solids have long been observed with nuclear detectors in the form of tracks in the material bulk, caused by impact of high energy $(\mathrm{MeV})$ charged particles. Presently, much effort is devoted towards the understanding of the interaction of SVHCIs with solid surfaces. With the recent development of electron beam ion traps (EBIT), which allow the extraction of highest charged ions at kinetic energies in the $\mathrm{keV}$ range, the formation of surface defects has been made possible [1][2][3]. Investigation of the underlying mechanisms of surface defect formation is of interest for understanding the basic physics of ion solid interactions as well as for possible nanometer scale lithographic applications due to ion induced surface modifications.

The LLNL EBIT2 provides ions with charge states up to $q \approx 80+$ which carry up to $\geq 200 \mathrm{keV}$ potential energy. Atomic force microscopy makes it possible to examine the defect topography on a $\mathrm{nm}$ scale qualitatively and, to a lesser extent, quantitatively. The latter, however, is still limited due to uncertainties in the AFM tip-surface interaction and tip shape effects. 


\section{Experimental}

The ions used for irradiation of the targets were extracted using the LLNL EBIT 2 [3][4]. It generates highly charged ions by successive electron impact ionization from an electron beam: Atoms from a gas source or lowly charged ions from a metal are source (MeVVA) are injected into the trap volume, where they are radially confined by the space charge of the electron beam while a drift tube assembly, consisting of three differently biased segments, provides axial confinement. To extract the ions, the potential of the middle drift tube is raised so that the ions can overcome the potential well. The charge state distribution of the extracted ions is determined by the confinement time, i.e. the time they are subjected to the electron beam impact. The target material is mica, a phyllosilicate with the sum formula $\mathrm{KAl}_{2}(\mathrm{Si} 3 \mathrm{Al}) \mathrm{O}_{10}(\mathrm{OH})_{2}$, which consists of layers with a net negative charge bonded through interlayer cations. This structure results in an excellent cleavage behaviour providing very flat surfaces.

Freshly cleaved samples of muscovite mica were irradiated with different ions: $\mathrm{Xe}^{1+}, \mathrm{Xe}^{35+}, \mathrm{Kr}^{35+}, \mathrm{Xe}^{44+}, \mathrm{Xe}^{50+}, \mathrm{U}^{70+}$ and $\mathrm{Th}^{74+}$ extracted at a velocity of $2.2 \mathrm{keV} / \mathrm{amu}$ and fluences of $10^{9}-10^{10}$ ions $/ \mathrm{cm}^{2}$. The vacuum along the beam path and in the target area was ca. 5•10-9 Torr. The ion flux was measured with a detection system consisting of a microchannel plate array or photomultiplier, with an ion detection efficiency between 30 and $60 \%$ depending on the details of the actual setup. The fluence was typically achieved in a $1-10 \mathrm{~h}$ irradiation, depending on the ion species. 
A series of irradiations was performed at different velocities: 1.3, 2.2 and $4.5 \mathrm{keV} / \mathrm{amu}$. After irradiation the targets were stored in air until being imaged with the AFM.

\section{AFM of the irradiated surfaces}

The irradiated samples were imaged with two different commercial AFMs: Nanoscope III (Digital Instruments) and Autoprobe LS (Park Scientific Instruments). The AFM images topographical structures of a surface by scanning it with a very sharp tip attached to a cantilever. The bending of the cantilever which is a measure of the height change on the surface and is monitored via a laser beam, reflected off the cantilever onto a photosensitive detector. An electronic feedback loop is used to adjust the height of the sample at every point, thus keeping the cantilever deflection constant. With the Nanoscope III a pyramidal $\mathrm{Si}_{3} \mathrm{~N}_{4}$ tip of aspect ratio $1: 1$ was used which was attached to a cantilever with a nominal rigidity of $1 \mathrm{nN} / \mathrm{nm}$. The tip used with Autoprobe LS is a conically shaped Si tip with an aspect ratio of $3: 1$ and rigidity of the cantilever of $0.6 \mathrm{nN} / \mathrm{nm}$. The tip radius is $20-80 \mathrm{~nm}$ for the pyramidal tip and an alleged $10 \mathrm{~nm}$ for the conical tip [5]. All of the samples were measured with the Nanoscope III shortly after the irradiation and the samples irradiated with $\mathrm{Kr}^{35+}, \mathrm{Xe}^{44+}$ and $\mathrm{U}^{70+}$ were remeasured after one year with the Autoprobe LS. Results for height and width of the defects were obtained by assuming a linear background and measuring the full width and height of the defect with respect to that background. Assuming a spherical shape of the defects, 
the volume was then obtained by: $\mathrm{V}=\mathrm{w}^{2} \cdot \mathrm{h} / 2$. The noise on both instruments is still on the order of a few $\AA$, so that very small defects, with a volume less than $10 \mathrm{~nm}^{3}$, according to a rough estimate, can not be detected.

\section{Results and Discussion}

Observation of the sample surface showed that blisterlike defects had been generated during irradiation (Fig 1). Their shape is independent of the scanning direction (Fig 2) indicating real topographic structures, rather than features due to alteration of the friction coefficient [6]. The density of the defects, which is comparable to the ion fluence, indicates that they are caused by single ion impact. They range from 0.1 to $3 \mathrm{~nm}$ in height, although most vary between 0.5 and $2 \mathrm{~nm}$. The width appears to be on the order of 10 to $60 \mathrm{~nm}$. Figs 3 and 4 show the height, width and volume of the defects caused by different incident ions as measured with the two different AFMs. It is obvious that the height and width measurements vary significantly between the two instruments which is partly due to uncertainties in the setup of Autoprobe LS. Furthermore the use of Si tips could lead to the measurement of larger widths since they are very brittle and could break off during measurement leaving a tip with a large radius not being able to resolve defect widths smaller than its own diameter due to convolutionary effects. The measured defect heights are similar for both instruments although the data points for $\mathrm{Xe}^{50+}$ and $\mathrm{Th}^{74+}$ using the Nanoscope III are not understood. These measurements could not be repeated due to sample contamination. The 
height measurement is expected to be sensitive to the force exerted by the AFM cantilever, it is therefore possible that the defects were squeezed down. The estimated volume, however, increases linearly with charge state of the incidention, which is found in both cases, see Fig. 4.

No defects were seen on mica irradiated with $\mathrm{Xe}^{1+}$ or $\mathrm{Xe}^{35+}$. The defect size was not found to depend on the velocity of the projectile, which had been varied over the range of $1.3-4.5 \mathrm{keV} / \mathrm{amu}$. Mica samples of different composition seem to yield different size defects, a systematic study of this effect is underway. Fig 5 shows the stability of the defects over time and the reproducibility of the irradiation. The volume measurement has been reproduced within $5 \%$.

The mechanism by which the defect formation is governed is not yet understood. One model follows the ion explosion spike model by Fleischer et al. [7] which has been introduced to explain the formation of nuclear tracks. The electrical field of the ion approaching the surface draws electrons out of the solid thereby charging it positively. The ions in this charged regions repel each other and, if the repulsive force exceeds the mechanical strength of the material, permanent atomic displacement occurs. A minimum threshold charge state is expected, which should be around $\mathrm{q} \sim 30$, according to experimental observation. Considering the structure of mica, one expects the top layers to mutually repel each other and form a hollow blister, which would appear as a hillock during AFM measurement. The amount of charge of the incident ion then influences the strength of the electric field drawing electrons from the solid which in turn determines the size of the affected surface region. Therefore one expects the defect volume to increase with increasing charge state.In the case of conductors the increase of the electron 
emission with incident charge has been measured [9]. Defect production may also be associated with enclosure of neutral entities, indicated by the observaton that similar defects are caused by heating the mica substrate. Heating could lead to expansion of the trapped volumes or to disturbance of the charge balance by displacement of the interlayer cations. Although first investigations have shown formation of similar defects through SVHCI irradiation and heating it is not clear whether the same mechanism is responsible in both cases or whether they are of a different nature.

\section{Conclusion}

Defect formation due to irradiation of muscovite mica with SVHCI has been described. Although AFM investigation of the defects has revealed an effect of the incident charge state on the defect size which increases with increasing projectile charge there are still large uncertainties in the absolute dimensions of the defects involved and the underlying mechanisms are not yet understood. It has been shown that defects are not uniquely caused by irradiation but are also generated by sample heating. The studies are to be extended to AFM investigation on a sub $\mathrm{nm}$ scale as well as systematic irradiation of different kinds of mica. 


\section{Acknowledgement}

This work was performed under the auspices of the U.S. Dept. of Energy by Lawrence Livermore National Laboratory under contract No. W7405-ENG-48.

\section{Figure captions}

Fig. 1. AFM image of mica irradiated with slow $U^{70+}$ ions. The perspective view shows blisterlike defects with a full diameter of 30 to $50 \mathrm{~nm}$ and a width of 0.5 to $1 \mathrm{~nm}$.

Fig.2. Line section of two AFM scans of mica irradiated with $\mathrm{Xe}^{50+}$ ions . The scans, depicting the same two defects, were taken with opposite scan directions, showing that the defect appears as a blister independent of the scan direction.

Fig.3. Mean heights and widths of defects as a function of incident charge state determined with Nanoprobe III and Autoprobe LS. The error bars represent the statistical width of each distribution.

Fig. 4. Mean volumes of defects as a function of incident charge state determined with Nanoprobe III and Autoprobe LS. The error bars represent the statistical width of each distribution.

Fig. 5a. Mean volume distribution of defects caused by $\mathrm{Xe}^{44+}$ ions on various mica samples during different independent experiments. The error bars represent the statistical width of each individual distribution. 
Fig. 5b. Mean volume measurement results from one sample irradiated with $\mathrm{U}^{70+}$ ions measured several times over a period of time. The error bars represent the statistical width of each individual distribution.

\section{References}

[1] D. Schneider, M.A. Briere, J. McDonald and W. Siekhaus, Nucl. Instr. and Meth. B 87 (1994) 156

[2] D. Schneider, M.A. Briere, M.W. Clark, J. McDonald, J.Biersack and W. Siekhaus, Surf. Sci. 294 (1993) 403

[3] M.A. Briere, D. Schneider, J. McDonald, M. Reaves, C. Ruehlicke, G. Weinberg and D.Knapp, Nucl. Instr. and Meth. B. 90 (1994) 231

[4] M.A. Levine, R.E. Marrs, J.R. Henderson, D.A. Knapp and M.B. Schneider, Phys. Scripta T 22 (1988) 17

[5] D.Schneider, M. Clark, B.M. Penetrante, J. McDonald, D. DeWitt and J.N.Bardsley, Phys. Rev. A 44 (1991) 3119

[6] R. Howland: "How to buy a scanning probe microscope", Park Scientific Instruments, 1993

[7] T. Hagen, S. Grafstroem, J. Ackermann, R Neumann, C. Trautmann, J. Vetter, N. Angert, J. Vac. Sci. Technol, B, V12 N3 (1994) 1555

[8] R.L. Fleischer, P.B. Price and R.M. Walker, J. Appl. Phys. 36 (1965) 3645

[9] F. Aumayr, H. Kurz, D. Schneider, M.A. Briere, J.W. McDonald, C.E. Cunningham and H.P. Winter, Phys. Rev. Let. V71 N12 (1993) 1943 


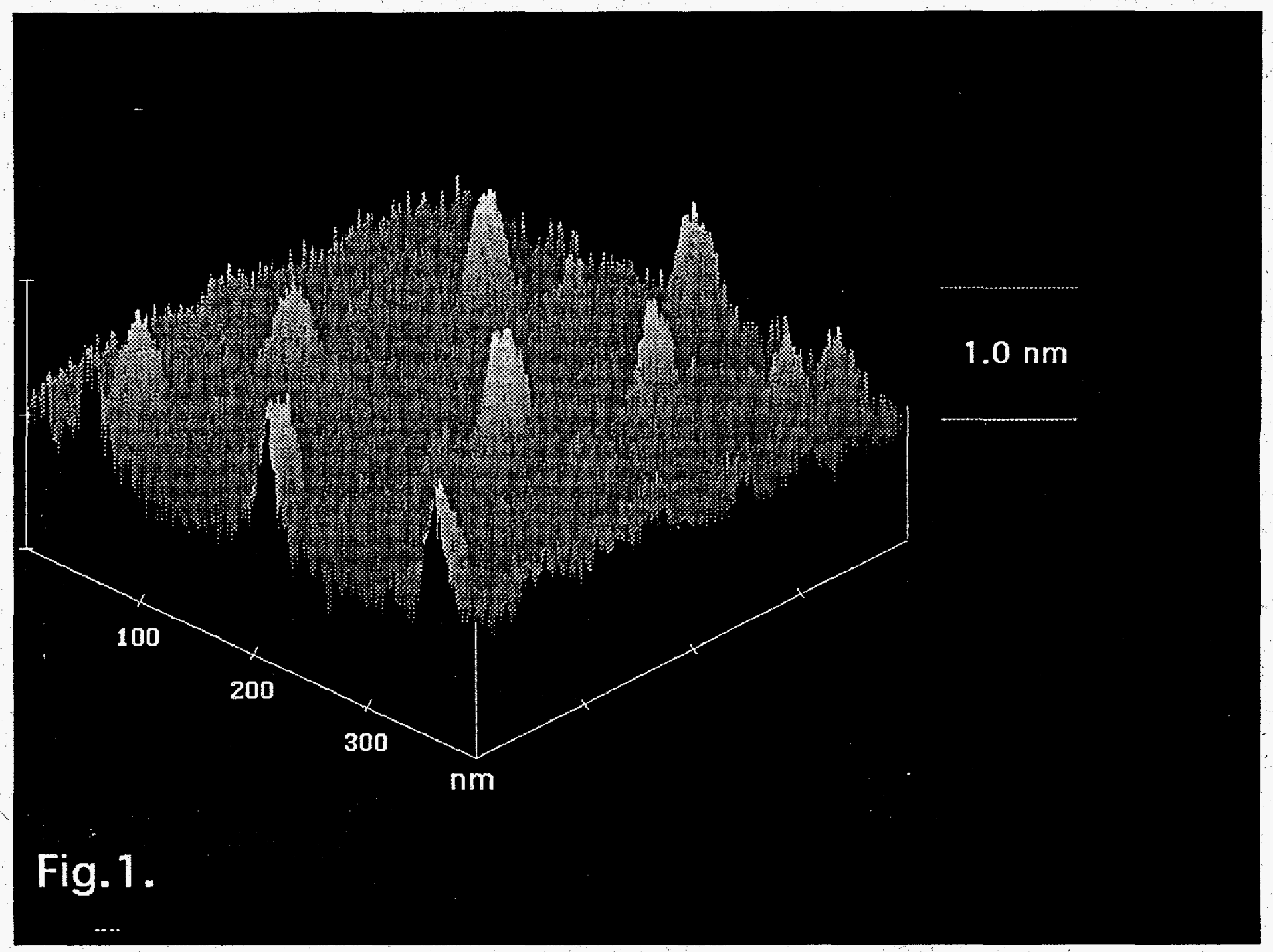



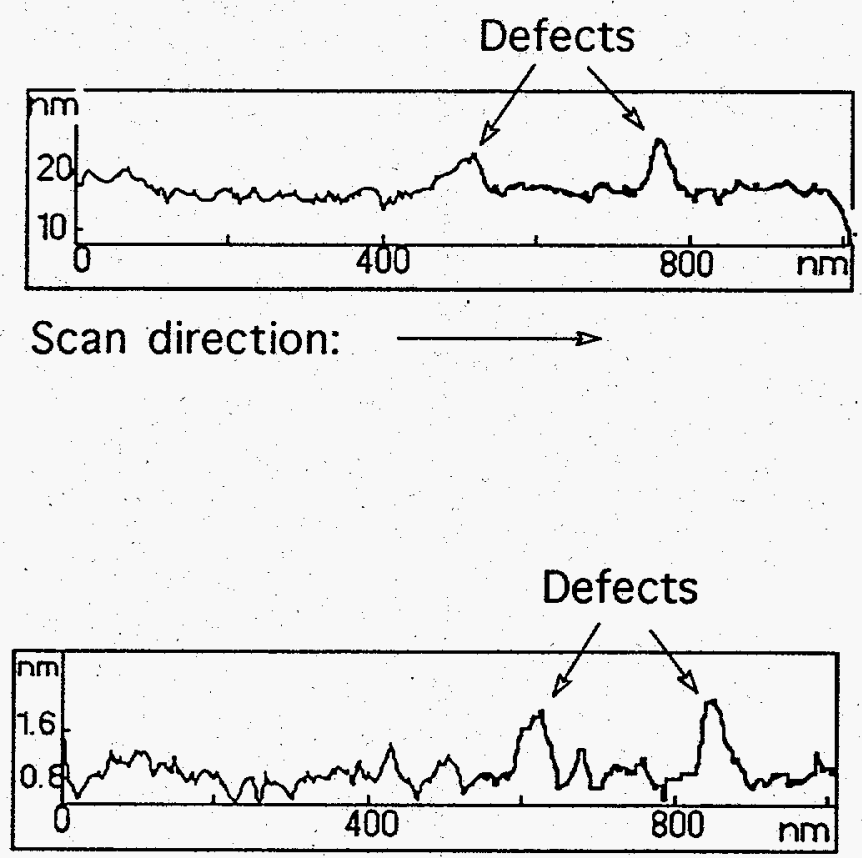

Scan direction:

Fig. 2. 

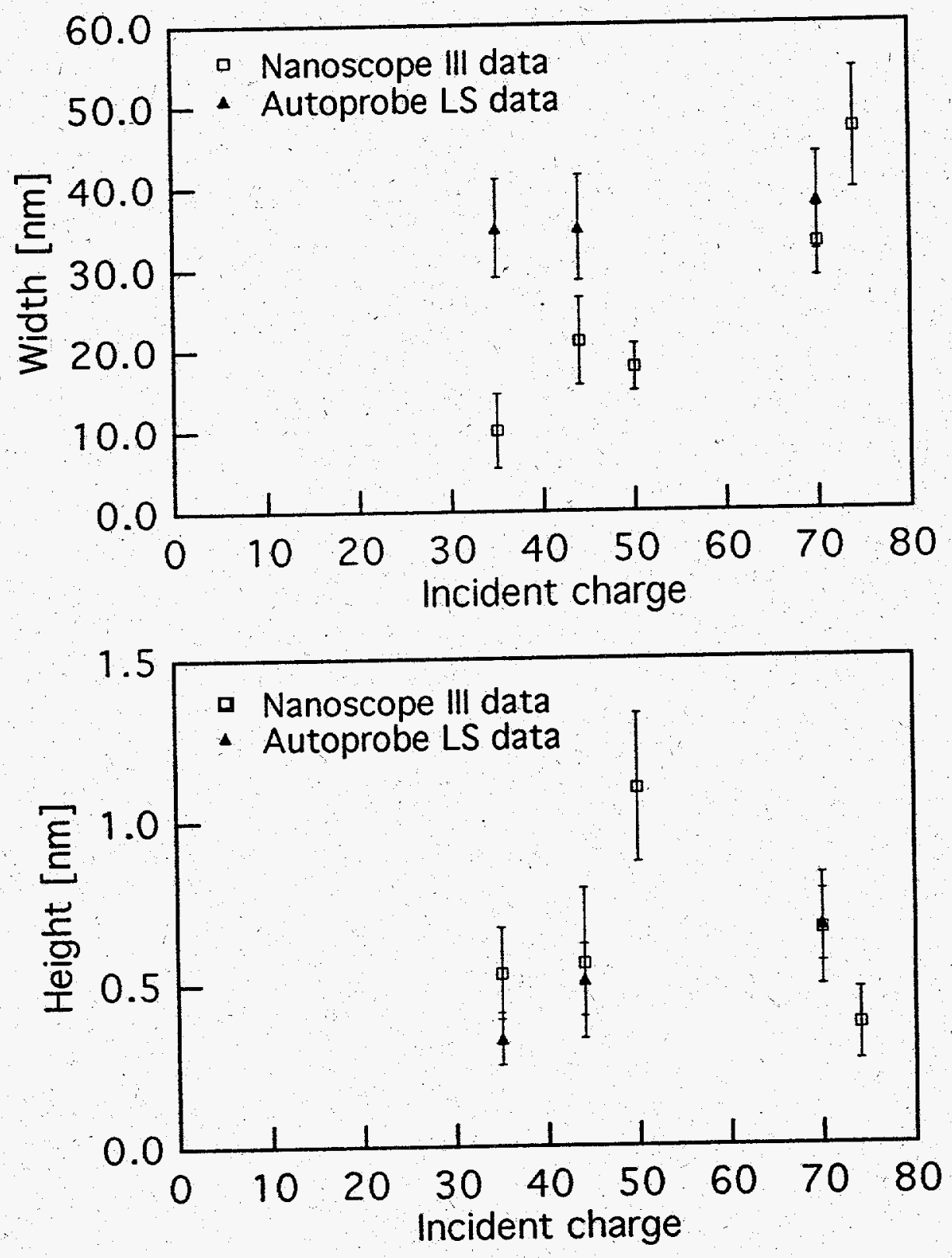

Fig. 3. 

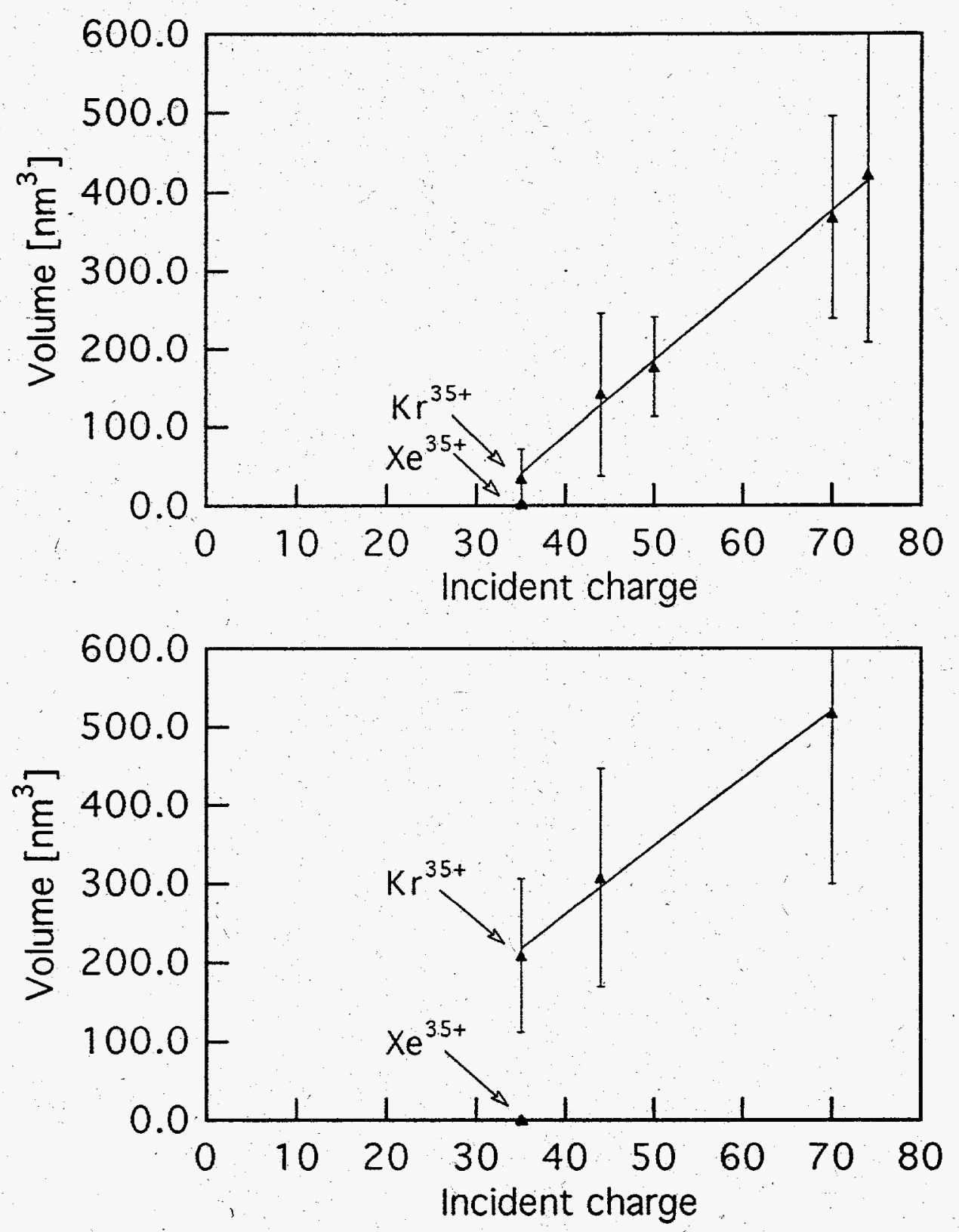

Fig. 4 . 

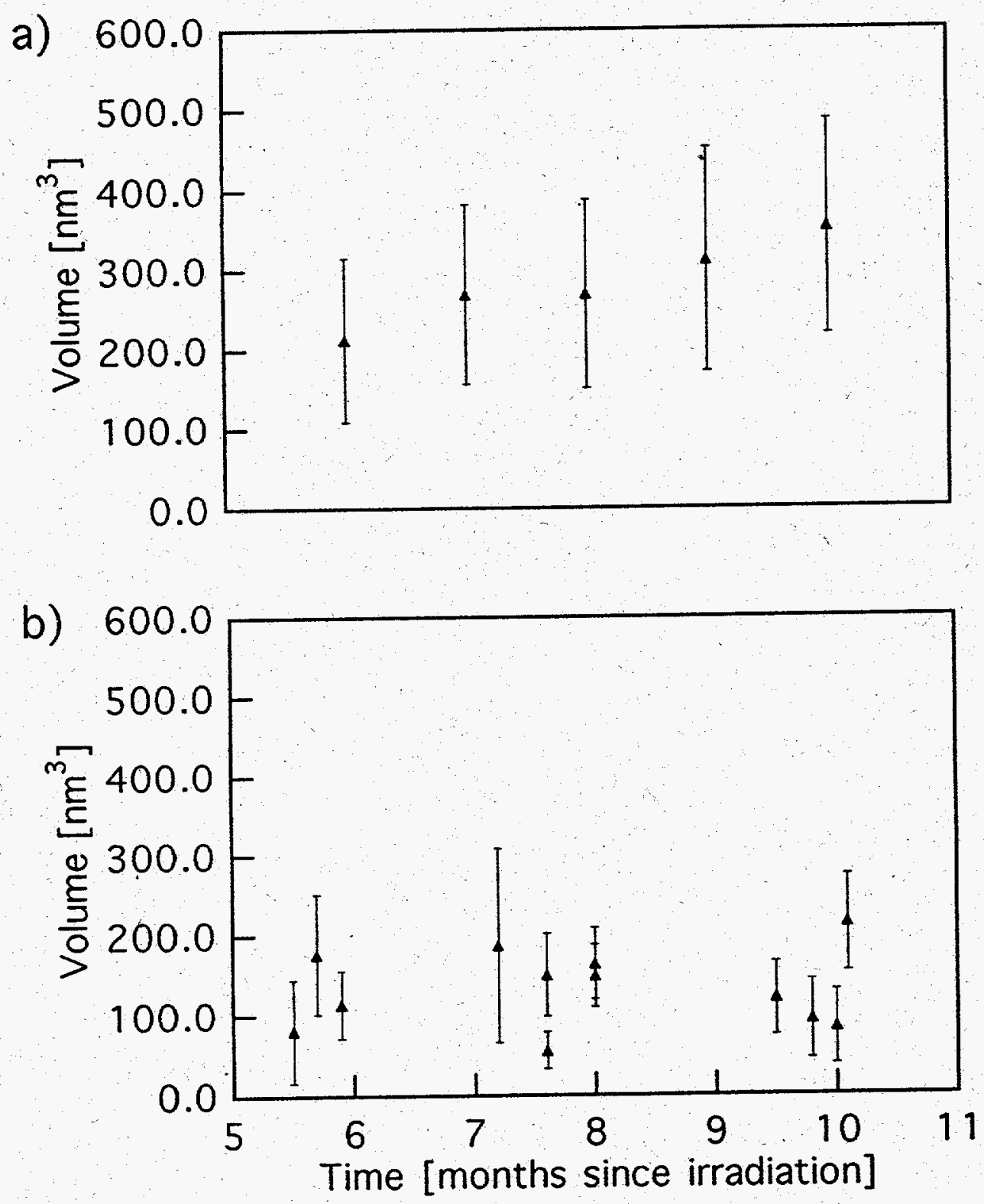

Fig. 5 